\title{
PERANCANGAN WEBSITE APLIKASI PENJUALAN RESTORAN AYAM KEPRABON
}

\author{
THE DESIGN OF SALES APPLICATION WEBSITE AYAM KEPRABON \\ RESTAURANT \\ Ignatius Adrian Mastan ${ }^{1)}$ \\ ${ }^{1)}$ Program Studi Akuntansi, Universitas Katolik Darma Cendika, Surabaya
}

Diterima 21 Juli 2019 / Disetujui 14 Agustus 2019

\begin{abstract}
The development of information technology has increased in all aspects of human life. All human activities today have used information technology and are getting easier, one of which is the transaction of ordering food in restaurants. Buyers do not need to come to the restaurant to make a purchase transaction, by using a smartphone they can open a website to order and buy food by online. With the increasingly sophisticated information technology, every business must be able to compete with success in the same business so as not to be left behind and displaced by others.

The restaurant that needs this sales application is the Ayam Keprabon Restaurant. Ayam Keprabon Restaurant has 45 outlets in several cities, namely: Jakarta, Depok, Tangerang, South Tangerang, Bekasi, and Bogor. With this Website-Based Sales Application, buyers can view restaurant profiles, food \& beverage menus, make orders, make payments, check order delivery status, register new members, place reservations. With this site-based sales application, it can increase sales and increase the competitiveness of Ayam Keprabon Restaurant with competitors who have implemented information technology in their business.
\end{abstract}

Keywords: sales application, website, restaurant, ayam keprabon

\section{ABSTRAK}

Perkembangan teknologi informasi telah berdampak pada seluruh aspek kehidupan manusia. Semua kegiatan manusia saat ini telah menggunakan teknologi informasi dan semakin dipermudah, salah satunya adalah transaksi pemesanan makanan di restoran. Pembeli tidak perlu datang ke restoran untuk melakukan transaksi pembelian, dengan menggunakan smartphone mereka dapat membuka website untuk memesan dan pembayaran makanan secara online. Dengan adanya teknologi informasi yang sudah semakin canggih ini, setiap usaha bisnis harus dapat mampu bersaing dengan pesaing dalam bisnis yang sama agar tidak tertinggal dan tergusur dengan para pesaingnya.

Salah satu restoran yang membutuhkan aplikasi penjualan ini adalah Restoran Ayam Keprabon. Restoran Ayam Keprabon memiliki 45 outlet yang tersebar di beberapa kota yaitu : Jakarta, Depok, Tangerang, Tangerang Selatan, Bekasi, dan Bogor. Dengan adanya Aplikasi Penjualan Berbasis Website ini, pembeli dapat melihat profil restoran, menu makanan \& minuman, melakukan pemesanan, melakukan pembayaran, mengecek status pengiriman pesanan, pendaftaran anggota, reservasi tempat. Dengan adanya aplikasi penjualan berbasis website ini dapat meningkatkan penjualan dan meningkatkan daya saing Restoran Ayam Keprabon dengan para pesaing yang telah menerapkan teknologi informasi dalam bisnisnya.

Kata Kunci : aplikasi penjualan, website, restoran, ayam keprabon.

\footnotetext{
*Korespondensi Penulis:

E-mail : Ignatius@mti.gadjahmada.edu
} 


\section{PENDAHULUAN}

Perkembangan teknologi informasi telah berdampak pada semua kehidupan manusia. Teknologi informasi juga telah mengubah beberapa aktifitas dan perilaku manusia, berbagai aktifitas lebih dipermudah dan lebih cepat. Salah satu aktivitas yang semakin dipermudah dengan teknologi informasi adalah pemesanan makanan. Sebelum adanya teknologi informasi atau aplikasi pemesanan makanan, seseorang harus datang ke restoran dan melakukan pemesanan secara langsung, serta pembayarannya. Dalam hal ini sangat menguras waktu dan tenaga, karena selain harus datang secara langsung ke restoran, melakukan pemesanan, mengantri, melakukan pembayaran dan menunggu pesanan makanan selesai disajikan.

Salah satu restoran yang membutuhkan aplikasi penjualan ini adalah Restoran Ayam Keprabon. Restoran Ayam Keprabon memiliki 45 outlet yang tersebar di beberapa kota yaitu : Jakarta, Depok, Tangerang, Tangerang Selatan, Bekasi, dan Bogor. Beberapa permasalahan yang sedang dihadapi oleh Restoran Ayam Keprabon adalah belum adanya apalikasi penjualan yang dapat membantu meningkatkan volume penjualan, menurunnya jumlah customer dibandingkan dengan kompetitor sejenis yang telah mempunyai aplikasi penjualan.

Dengan adanya Aplikasi Penjualan Berbasis Website ini, pembeli dapat melihat profil restoran, menu makanan \& minuman, melakukan pemesanan, melakukan pembayaran, mengecek status pengiriman pesanan, pendaftaran anggota, reservasi tempat. Aplikasi Penjualan berbasis website ini dibuat dengan menggunakan metode pengembangan perangkat lunak waterfall. Metode ini memiliki beberapa tahapan antara lain : Perancangan Sistem, Analisis
Sistem, Desain Sistem, Pengkodean Peogram, Uji Coba Program, Implementasi Sistem dan Pemeliharaan Sistem.

Dengan adanya aplikasi penjualan berbasis website ini dapat meningkatkan penjualan dan meningkatkan daya saing Restoran Ayam Keprabon dengan para kompetitor yang telah menerapkan teknologi informasi dalam bisnisnya.

Dengan perkembangan teknologi informasi, seseorang tidak perlu lagi bersusah payah ke restoran untuk membeli makanan, cukup dengan menggunakan aplikasi ini customer dapat melakukan pemesanan dan pembayaran tanpa harus datang langsung ke Restoran dan semakin meningkatkan citra Restoran Ayam Keprabon.

\section{METODE PENELITIAN}

\section{Website}

Menurut MacDonald (2011) website adalah kumpulan halaman (page) web yang terdiri dari berbagai macam elemen seperti teks, gambar, video, tabel, dan lain sebagainya yang kemudian digabungkan untuk menjadi suatu tampilan website yang kita lihat di web browser.

Menurut Hidayat (2010) website dapat dikelompokkan berdasarkan fungsi, sifat, dan bahasa pemrograman yang digunakan.

1. Jenis-jenis website berdasarkan sifatnya:

a) Website dinamis - sebuah website yang menyediakan konten yang dapat berubah-ubah setiap saat.

b) Website statis - website yang konten atau isi halaman websitenya yang akan berubah jika file nya diubah.

2. Jenis-jenis website berdasarkan tujuannya:

a) Personal website - website yang berisi informasi pribadi seseorang.

b) Corporate website - website yang dimiliki dan dikelola oleh sebuah perusahaan. 
c) Portal website - website yang mempunyai banyak layanan, seperti layanan email, berita, dan jasa-jasa lainnya.

d) Forum website - website yang dibuat dengan tujuan sebagai media diskusi.

3. Jenis-jenis website ditinjau dari bahasa pemrograman yang dipakai:

a) Server Side Website - website yang menggunakan bahasa pemrograman yang tergantung pada pihak penyedia server. Contohnya: ASP.

b) Client Side Website - website yang tidak memerlukan server dalam menjalankannya dan dapat diakses melalui browser saja. Contohnya : HTML.

\section{Hyper Text Markup Language (HTML)}

Menurut MacDonald (2011) HTML adalah sebuah tampilan dokumen dan bahasa hyperlink-spesification. HTML mendefinisikan syntax dan arahan-arahan yang dituliskan dalam sebuah file yang dimaksudkan untuk menampilkan halaman pada web browser bagaimana isi dari dokumen, termasuk teks, gambar, dan media lainnya yang dieksekusi oleh HyperText Transport Protocol. HTML juga memberitahu bagaimana membuat dokumen menjadi interaktif melalui hypertext links khusus dengan menghubungkan antar dokumen pada komputer

Menurut Sibero (2011) Hyper Text Markup Language (HTML) adalah bahasa yang digunakan pada dokumen web sebagai bahasa untuk pertukaran antar dokumen web. Dokumen HTML terdiri dari komponen yaitu tag, elemen dan atribut. Tag adalah tanda awal < dan tanda akhir > yang digunakan sebagai pengapit suatu elemen. Elemen adalah nama penanda yang diapit oleh tag yang memiliki fungsi dan tujuan tertentu pada dokumen HTML. Elemen dapat memiliki elemen anak dan juga nilai. Elemen anak adalah suatu elemen yang berada didalam elemen

pembuka dan elemen penutup induknya. Nilai yang dimaksud adalah suatu teks atau karakter yang berada diantara elemen pembuka dan elemen penutup. Atribut adalah properti elemen yang digunakan untuk mengkhususkan suatu elemen. Elemen dapat memiliki atribut yang berbeda pada tiap masing-masingnya.

\section{Model Waterfall}

Metode air terjun atau yang sering disebut metode waterfall sering dinamakan siklus hidup klasik (classic life cycle), dimana hal ini menggambarkan pendekatan yang sistematis dan juga berurutan pada pengembangan perangkat lunak, dimulai dengan spesifikasi kebutuhan pengguna lalu berlanjut melalui tahapan-tahapan perencanaan (planning), permodelan (modeling), konstruksi (construction), serta penyerahan sistem ke para pelanggan/pengguna (deployment), yang diakhiri dengan dukungan pada perangkat lunak lengkap yang dihasilkan (Pressman, 2012). Tahapan metode waterfall dapat dilihat pada gambar di bawah ini.

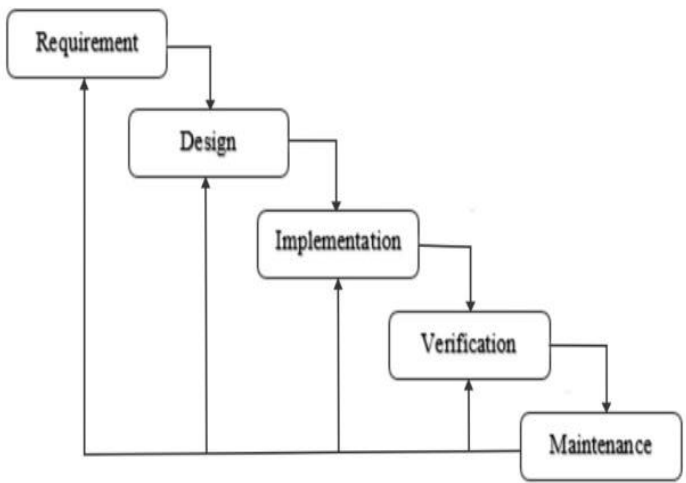

\section{Gambar 1 Model Waterfall}

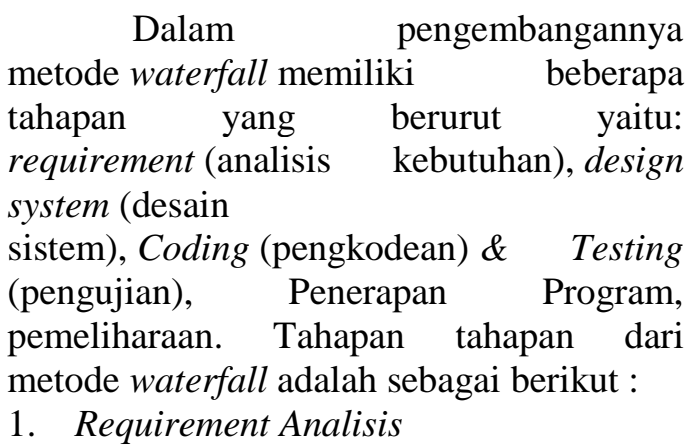


Tahap ini pengembang sistem diperlukan komunikasi yang bertujuan untuk memahami perangkat lunak yang diharapkan oleh pengguna dan batasan perangkat lunak tersebut. Informasi ini biasanya dapat diperoleh melalui wawancara, diskusi atau survei langsung. Informasi dianalisis untuk mendapatkan data yang dibutuhkan oleh pengguna.

2. System Design

Spesifikasi kebutuhan dari tahap sebelumnya akan dipelajari dalam fase ini dan desain sistem disiapkan. Desain Sistem membantu dalam menentukan perangkat keras(hardware) dan sistem persyaratan dan juga membantu dalam mendefinisikan arsitektur sistem secara keseluruhan.

3. Implementation

Pada tahap ini, sistem pertama kali dikembangkan di program kecil yang disebut unit, yang terintegrasi dalam tahap selanjutnya. Setiap unit dikembangkan dan diuji untuk fungsionalitas yang disebut sebagai unit testing.

4. Verification

Seluruh unit yang dikembangkan dalam tahap implementasi diintegrasikan ke dalam sistem setelah pengujian yang dilakukan masing-masing unit. Setelah integrasi seluruh sistem diuji untuk mengecek setiap kegagalan maupun kesalahan.

5. Maintenance

Tahap akhir dalam model waterfall. Perangkat lunak yang sudah jadi, dijalankan serta dilakukan pemeliharaan. Pemeliharaan termasuk dalam memperbaiki kesalahan yang tidak ditemukan pada langkah sebelumnya. Perbaikan implementasi unit sistem dan peningkatan jasa sistem sebagai kebutuhan baru.

\section{HASIL DAN PEMBAHASAN}

Tahapan Pengembangan Sistem Life Cycle memberikan urutan kegiatan dalam mendesain sistem dan mengembangkan perangkat lunak (software). Hal ini sering dianggap sebagai bagian dari siklus hidup pengembangan sistem (Mishra \& Dubey, 2013).

System Development Life Cycle (SDLC) dalam pembuatan aplikasi penjualan ini memiliki beberapa tahap :

\section{A. Requirement Analysis}

Tahap pengumpulan kebutuhan sistem digunakan untuk menspesifikasikan kebutuhan sistem yang dibutuhkan oleh user. Pengumpulan kebutuhan berupa data input, proses yang terjadi, serta output yang dihasilkan.

1. Identifikasi Masalah

Beberapa identifikasi masalah di Restoran Keprabon adalah :

- Banyaknya kompetitor restoran sejenis yang telah menggunakan sistem informasi, baik berupa website dan mobile application.

- Customer kesulitan dalam mengetahui menu apa saja yang tersedia di restoran.

- Customer kesulitan dalam melakukan pembelian, dan pembayaran, dikarenakan harus datang langsung ke restoran

- Customer mempunyai keterbatasan dalam melakukan pemesanan (reservation) ruangan untuk acara mereka di Restoran Ayam Keprabon.

2. Identifikasi Kebutuhan Informasi

a) Identifikasi Data Customer

b) Identifikasi Data Restoran

- Data Cabang Restoran

- Data Lokasi Restoran

- Data Ruangan

c) Identifikasi Data Menu

- Data Jenis Menu

- Data Menu

d) Identifikasi Transaksi

- Data Reservasi

- Data Detail Reservasi

- Data Down Payment

- Data Transaksi

- Data Detail Transaksi 
- Data Jenis Pembayaran

\section{B. Design}

Proses ini berfokus pada desain database yang meliputi tabel-tabel yang digunakan di dalam aplikasi penjualan. Pada tahap ini, kebutuhan-kebutuhan yang terdapat di sistem diterjemahkan yang berasal dari tahap Requirement Analysis agar dapat diimplementasikan menjadi program di tahap selanjutnya. Pada tahap Design ini, dilakukan pembuatan Entity Relationship Diagram (ERD) untuk menggambarkan usulan sistem yang ditawarkan, dapat dilihat pada gambar 2 .

\section{Development}

Pada tahap development, aplikasi website penjualan akan dikembangkan dengan menggunakan bahasa pemrograman yang diimplementasikan dalam bentuk coding untuk membentuk aplikasi penjualan yang sesuai dengan tahap design

\section{Testing}

Pada tahap testing, seluruh proses yang dikerjakan dalam tahap development dilakukan testing atau pengujian untuk mengecek apakah prosesnya sudah berjalan sesuai dengan yang direncanakan. Jika ditemukan ketidaksesuaian, maka akan segera dilakukan perbaikan.

\section{E. Maintenance}

Pada tahap maintenance, aplikasi yang sudah siap untuk digunakan dan dijalankan dapat dilakukan perbaikan-perbaikan untuk menyempurnakan aplikasi yang sedang dirancang tersebut. Untuk dapat diimplementasikan dengan menghindarkan kesalahan-kesalahan

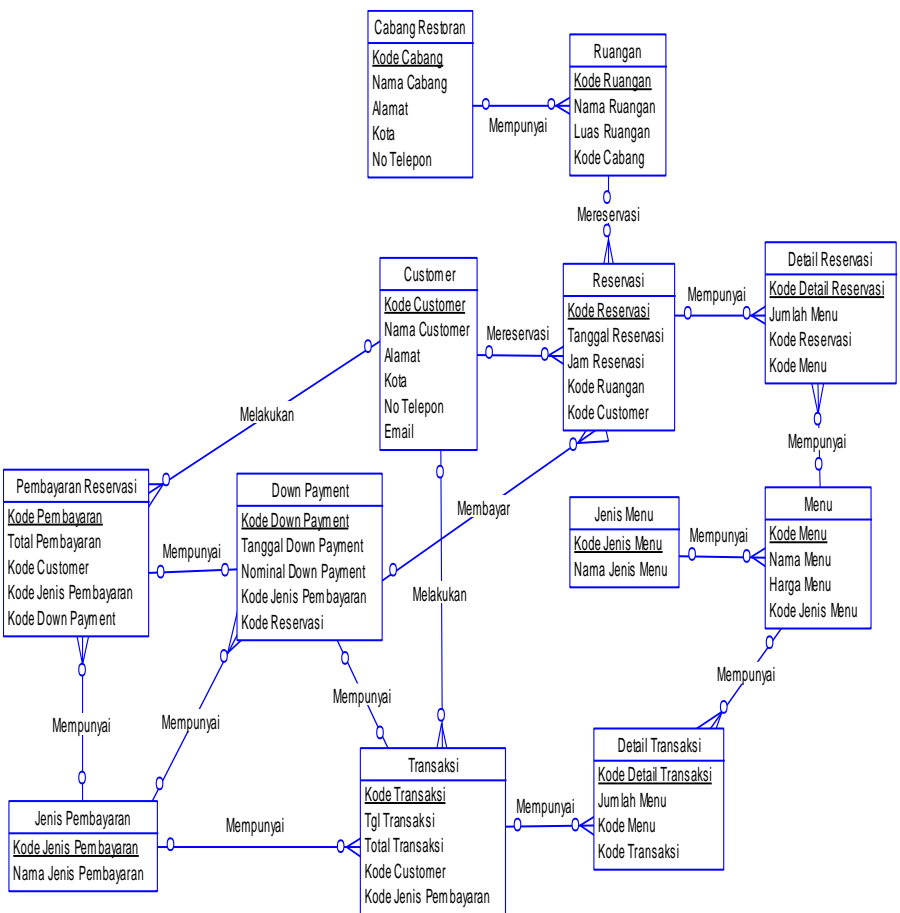

Gambar 2 Entity Relationship Diagram

\section{Implementasi Sistem}

Aplikasi Penjualan berbasis website Restoran Ayam Keprabon dirancang dengan menu Home, Profil Restoran, Menu, Reservation, Contact Us. Pada halaman Home digunakan untuk customer melakukan pendaftaran sebagai anggota Restoran Ayam Keprabon sebelum melakukan reservasi dan pemesanan makanan. Halaman Profil Restoran berisi mengenai sejarah dan cabang Restoran Ayam Keprabon.

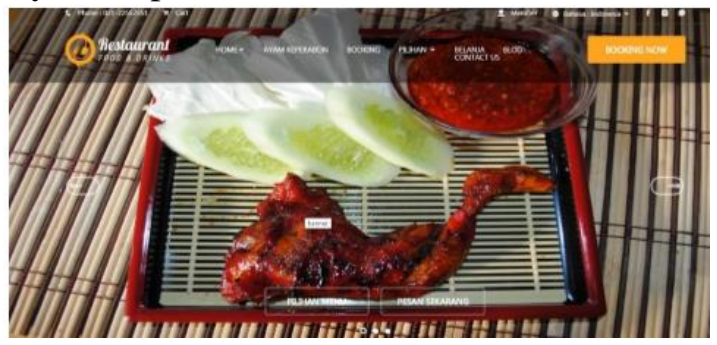

Gambar 2. Menu Homepage

Dalam halaman menu berisi mengenai daftar menu makanan, minuman dan lainnya yang disediakan oleh Restoran Ayam Keprabon. Customer dapat memilih daftar menu, harga dan melihat detail dari 
menu-menu yang disediakan, serta dapat melakukan pemesanan menu dan jumlah yang akan dipesan. Setelah selesai memilih menu dapat menekan tombol submit dan dilanjutkan dengan melakukan pembayaran dengan menggunakan kartu kredit, kartu debit, mobile banking, dan model pembayaran lainnya. Daftar menu dapat dilihat lebih detail pada Gambar 3.

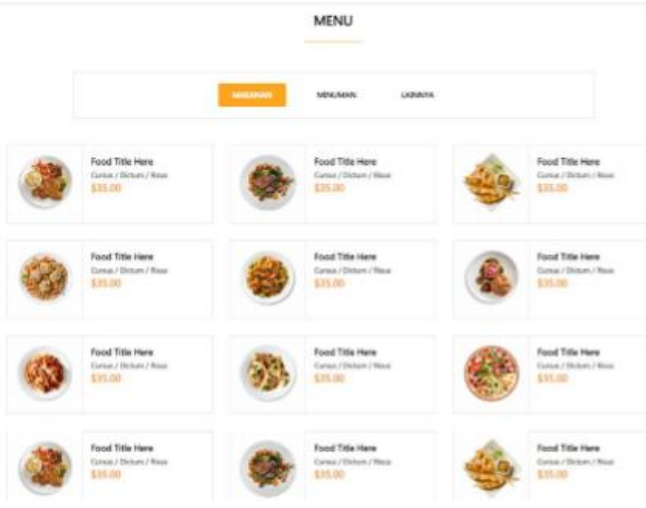

Gambar 3. Menu Makanan

Halaman reservation digunakan untuk melakukan reservasi restoran untuk kegiatan ulang tahun, pertemuan rapat, arisan, dan pertemuan-pertemuan lainnya. Customer dapat melakukan reservasi dengan memilih Cabang Restoran, tanggal dan jam untuk reservasi. Apabila jadwal sudah dipilih maka harus melakukan pemesanan menu makanan dan minuman dengan minimal transaksi tertentu dan harus melakukan pembayaran uang muka yang akan divalidasi sebelum reservasi disetujui. Pada halaman reservasi telah disiapkan sistem pengaturan yang menyebabkan tidak akan ada kegiatan yang saling bertabrakan dalam hal penjadwalan. Jika telah ada kegiatan pada Hari dan Jam yang telah direservasi maka jam pada tanggal tersebut tidak akan munvul dalam daftar pilihan.

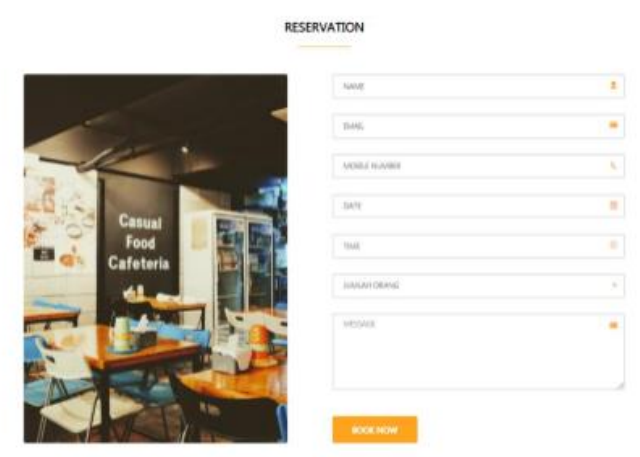

Gambar 4. Menu Reservation

\section{KESIMPULAN}

Dengan menggunakan aplikasi penjualan berbasis website ini, Restoran Ayam Keprabon dapat meningkatkan penjualan dan pendapatan restoran dan dapat bersaing dengan restoran-restoran lain sejenis yang telah memanfaatkan teknologi informasi dalam meningkatkan dan mengembangkan bisnisnya. Dengan adanya website penjualan ini, semakin mempermudah customer melakukan pembelian dan pembayaran, serta reservasi restoran tanpa harus mendatangi lokasi restoran ayam keprabon.

\section{DAFTAR PUSTAKA}

Hidayat, R. (2010), Cara Praktis Membangun Website Gratis. PT Elex Media Komputindo, Jakarta.

MacDonald, M. (2011), Creating a Website: The Missing Manual, $3^{\text {rd }}$ Edition, O'Reilly Media, California.

Pressman, Roger S. (2012). Rekayasa Perangkat Lunak - Buku Satu, Pendekatan Praktisi (Edisi 7). Yogyakarta: Andi.

Sibero, F. K. A. (2011), Kitab Suci Web Programming, Media Com, Jakarta. 